Masuma H. Mammadova, Zarifa G. Jabrayilova

DOI: 10.25045/jpit.v07.i1.05

Institute of Information Technology of ANAS, Baku, Azerbaijan

depart15@iit.ab.az

\title{
OPPORTUNITIES AND CHALLENGES OF BIG DATA UTILIZATION IN THE RESOLUTION OF HUMAN RESOURCE MANAGEMENT
}

The article analyzes the state of big data $(B D)$ integration in solving the problems of human resource management (HRM). It sheds light on the relevance of the use of $B D$ for making more objective and wise decisions in the resolution of HRM issues. Some applications, pertinent to BD and HRM objectives, are highlighted and integration opportunities, prospects and problems are presented. Some recommendations are proposed for the successful integration of BD and HRM objectives.

Keywords: big data, human resource management, decision-making, personnel recruitment.

\section{Introduction}

Since 1980, digital data has been doubling approximately every 40 months [1]. Since 2012, 2.5 Exabyte ( $2.5 \times 1060$ bytes) information has been extracted daily [2]. However, $90 \%$ of data, growing at exponential rates, either has not been taken into account, or analyzed [3].

The process of large-scale data generation occurs at all levels of society, which predicts about the "worst big data" century [4]. BD is a data collection, the processing of which is beyond the capabilities of collection, storage, management and analysis tools of traditional databases. In this sense, large-scale data processing becomes difficult by means of traditional systems, and it is analyzed in order to obtain important information and knowledge by establishing the correlation between the data.

The authors of [5] note the importance of the use of BD and highlight BD Analytics (BDA), which improves decision-making. They argue that by using the BDA, it is possible to realize forecasting issues in all fields. Giant companies as IBM, HP, Cape Gemini, SAP, Accenture, Oracle Corporation, Microsoft have already implemented the realization of BD.

Thus, the trend toward the use of BD is integrated into management issues of all organizations, as well as the HRM. Thus, given HRM includes variety of issues such as planning, organizing, control, routing, recruitment, selection and placement, performance appraisal, qualification, motivation and so on, the amount of information generated in this system can be imagined. Nevertheless, even containing such amount of information, traditional HRM systems experience acute challenges to give information about the further development of employees and their career promotion. In this regard, the usage of BD in HRM can support more precise and objective (wise) decision making in the relevant management issues [6].

\section{Integration of BD in HRM Issues}

As the enterprise grows over time, the volume of information about its employees increases dramatically. On the other hand, old data about previous employees may be required for a variety of reasons. Skills, behavior and competencies of each employee, in an Individual and organizational level, is increasing the volume of the information about him/her progressively. Overall, the HRM systems should ideally provide the followings [7]:

- storing professional archive of each employee;

- results of multiple (multi-criteria) collections of candidates for vacancies;

- results of certification of personnel by taking testing methods into account;

- ranked reserve personnel database;

- assessment results of labor activity (including administrative capacity) of employees (periodically).

Such systems allows for: 
- isolation from additional colleagues;

- identifying negative cases in the company;

- controlling the costs spent for the personnel development trainings;

- diagnosing motivation;

- developing motivation mechanisms to increase interest of the employees;

- developing the modern system of personnel sourcing and recruitment;

- optimal placement of personnel;

- designing the new vacancy structure of the company;

- analyzing quantitative and qualitative parameters of personnel and so on.

If the availability, convenient and quick use of all this data is not properly organized, it may be useless and negligible. On the other hand, large-scale data related to human resources or obtained from various sources is now available for use. Such sources may include:

$>$ web pages;

$>$ personal profiles created by candidates on social networks;

$>$ e-mail, documents, overviews, and notes created by people;

$>$ sensors, video cameras, and other technical parameters of the devices tracking the employees' behavior, which are primarily related to the data forming the attitudes about the employee and provide its availability.

At present, decisions making in the field of human resources is rather based on the analysis of this data than practice and forecasts.

Apparently, the complexity of the administration and loading with large-scale, complex and inconsistent information requires the regulation of various structured and unstructured information necessary for decision-making by the authority of different levels. The higher the administration is, the more the information should be aggregated. Top-level manager is able to make decisions, based on deep processing of low-level information, and in this case, he/she refers to the key indicators of performance related to specific problem solution rather than the various indicators and graphical figure sets. In this regard, the integration of BD into HRM decision-making issues guarantees the phase of wisdom on DIKW model (Data, Information, Knowledge, Wisdom) [8].

Knowledge-based human resource management has been achieved only after the emergence of appropriate technologies and software products. Now, we can state that the most obvious example of the computer industry ERP (Enterprise Resource Planning) is used, which supports enterprise resource management systems. ERP systems enable to increase the efficiency of enterprise operations (accounting, payment control, payment of the bills, and acceleration of investment reimbursement). However, the users of these systems are lower-or-middle-level managers, and top-level managers still do not benefit from them.

That is why BDA helps to achieve high quality and cost effectiveness in all phases of HRM. In HRM, BDA determines the relations between important information and the data required for decision-making and development of any organization, by analyzing structured and unstructured data. Each data may contain the characters, numbers and so on, which do not make any sense separately, however, their interpretation may be of great importance in predicting the future, and may be used in making wise decisions regarding HRM. Thus, the use of BD in HRM provides development, competitiveness, speed and satisfaction (transparency between employees and management) of the organization [3, 6].

The interaction of HRM and BD is relevant; it is required to establish a strategy that allows the rise of the organization and realization of its hidden potentials. However, not all organizations are ready to contact HRM systems, even though they have been implementing some automated management processes (business processes) over the last several decades. This is due to the fact that very few organizations exploit the ERP systems to provide the collection of necessary data. These systems now support all the elements of human resource management: selection of candidate (recruitment), planning, training, appraisal, placement and re-placement, motivation and so on (e.g. SAP (founded in Germany in 1972, annual turnover of more than 14 billion), Gartner 
(USA), BAAN (founded in the Netherlands in 2003), Scala (founded in Sweden in 1978), Navision (founded in Denmark in 1983 and used in Norway, Germany, Spain, England, the United States) and so on.), while they were designed for accounting and payroll of the personnel in the first period.

The use of BD in HRM is possible only through the implementation of these systems, hence integration of BD into HRM consists of the following steps [9]:

Step 1: personal decisions. Companies did not have human resources (HR) systems on the data collection before, and therefore, decisions were based on the experience gained in this field;

Step 2: use of internal information. The systems assisting data collection were established, and simple data collection started to support HRM decisions (i.e., economic expediency);

Step 3: establishment and use of internal standards. HR Services began to make their own decisions not only within the framework of their data, but also by examining the data (searching candidates for vacant positions from internal reserves, forming corporate standards) within the company.

Step 4: conducting in-depth analytics. At this stage marketing is taken towards analytics, the studies on the analysis of company flow and attraction are accelerating. Mixed trends within the company are analyzed at this stage.

Step 5: forecasting. HRM service uses BD to determine the impact of the decisions related to human resources on the further development of the company. The data, which determines the future development of the company is defined by the data within the company, namely the data about finance, marketing, sales and those collected in HRM systems, and by the external data about competitors, market, economic and political situation in the country.

Today Oracle, SAP, Workday, ADP, Ultimate, Infor (Lawson) and core HR service providers offer their own solutions in clouds to HRM for planning, deployment, re-deployment and so on, Cornerstone On Demand (increased by $61 \%$ recently), Silkroad, SumTotal, Lumesse, Halogen, Peoplefluent, Саба, Kenexa (developed by IBM) offer their solutions for talents management [10]. These solutions enable HRM managers to prevent modernization problems of the corporation annually or biennially. Conducted studies show that only $13 \%$ of companies use core HR system, companies exploit about 3-4 HRM system applications (for example, training (qualification) system, talents management (TM), workforce management systems (WFM)) [10]. In December 2011, Aberdeen Group conducted survey in more than 126 organizations which appreciate the introduction of BD in HRM. They conclude that the organizations using core HR, TM, WFM systems are more satisfied with their performance [3].

At present, BD in HRM is used in two directions, which are talents management and personnel recruitment.

\section{Use of BD in talents management}

In modern world, the competitiveness of any organization is defined by the knowledge and skills of its human resources, and therefore, attracting more skilled people to the company is the major concern of HR department. The traditional problem solution is accompanied by the following stages: first, the manager announces the vacancy; second, it is broadcasted on the corporate portal; third, those, who are interested, send the information about themselves; fourth, personnel specialist invites a suitable candidate to the interview, as this continues unless the appropriate candidate is selected. Education, sex, age, qualifications, experience on an interviewee play an important role during the recruitment. Nevertheless, the reality is that the results may sometimes be deceptive. A short interview may not give detailed information about the candidate. The interviewers only refer to the information provided by the candidate. Thus, giving unfair and sometimes false information causes distortions.

Google Inc. claims that successful outcome of the interview is not related to the further effective activity, and therefore, has refuses this stage [9]. The use of BD in this field allows 
removing these points. First of BD provides a wider platform for talents management, that is the Internet. Statistics shows that more than two-thirds of the enterprises in the People's Republic of China use online recruitment [11]. The company integrates it into the social networks, and collects initial important information, which is for BDA (for example, the candidates' CVs), and forms the foundation for the analysis of "big data". Moreover, even if there is no vacancy, such companies regularly collect information about the candidates. The information gathered from social networks help to get more detailed information about the candidates, for example, his videos, lifestyles, social attitudes, skills and so on, provides more clear and precise "portrait" [12]. One of the achievements of involving BDA was realized by eQquest-x BDA. BD and eQquest-x BDA is a social media with more than 1,000 career sites around the world, 1.5 billion working group, which present more than 250 million vacancies. They allow the companies planning the vacancies and forecasting its future development (success). Presenting vacancies based on BDA it is possible to analyze various data characterizing an employee's performance, and to find suitable candidates to each position more quickly and at a lower cost [13]. More than 60\% of companies study the data collected in BD and HRM Systems based on analytical tools, which changes the traditional activities of HR department revolutionarily.

Jupiter Networks has developed BD-based network infrastructure for the intelligent data acquisition in HRM department. The company uses social network Linkedin to explore potential employees [3]. Thus, the company always achieves to recruit potentially promising masters and doctors, and engineers.

\section{Application of BD in personnel training (qualification)}

Under the concept of the modern HRM, a personnel is a key element of any organization's sustainable development, and constant improvement of knowledge and skills of workers allows them to increase the productivity of the enterprise [14]. Traditional training is typically organized by the company. The company involves professionals and plans staff training after work or at home. Regardless of the methods, many companies have allocated financial, material and human resources for it. This type of preparation reminds traditional classroom training, which may not effectively meet various requirements of learners. The age of BD has a positive impact on the solution of this problem.

It is more convenient to use available data in the context of BD. Everyone may easily acquire the necessary information any time. In addition, many organizations are currently developing a network of professionals training courses. Each company can configure the network to the specific situation, and most companies have already formed this experience. Such software is able to record data according to each employee's behavior, and they may choose the form of education online that suits them using the system. Thus, the employee organizes his/her training more focused and increases its quality. The employee may take online test at any time, which increases effectiveness of the training. Such an approach allows forecasting an individual's level after a while according to indicators through a special program [15]. Moreover, such an approach provides the managers to control educational process and the personnel to gain new skills.

\section{Application of BD in performace appraisal}

According to the modern concept of HRM, assessment of the personnel is a very important point. Currently, the expert evaluation, test approach and complex assessment forms are more preferable. However, these methods are very personal. Therefore, researchers explore traditional practices, and study more effective assessment of the employees' performances and their classification issues through the use of BD technology [16]. In this context, assessment methods analyze the use of BD. At present, companies define the difference between the current status of any employee and his competency "portrait" with the use of BD in giant systems [17]. This diversity may base on technical expertise, skills, personal characteristics, and even psychological factors. The sources of these indicators may include monitoring the employee at the workplace (to track his working day by video cameras installed in the workplace), his attitudes about social networks, and behavior outside the work areas (e.g. by 
video cameras installed in public places, etc.). Such an approach is an innovation in building competency model, and recognized as the recruitment standard. On this basis, the application of BD in HRM will ensure wise decision making in the employees' evaluation.

\section{Application of BD to Motivate Employees}

Payroll system of each company is the most important indicator to involve employees, on the other hand, payment of the wages in accordince with the employee's performance by the manager is of great importance for his/her motivation. In fact, the reality is that the payroll system remains as ag problem for all companies [18].

Traditionally, the operating system of the workers is primarily reflected in more qualitative and less quantitative expression, in fact, the level of wages does not always coincide with the performance. Salary does not reflect the high and low performance (productivity) of the employee in real terms, which reduces the employees' responsibility. HRM managers also face difficulties with the evaluation of daily performance. However, the company can record daily workload of each employee, specific nature of the work, and how well the employee achieves the goal, and then may process and analyze the data in clouds [19]. Finally, salary may be paid automatically in accordance with quality standards. Besides increasing the efficiency of the work, the implementation of these operations can also reduce business investment in human capital. To this end, some companies have begun installation of video cameras to monitor the behavior of employees in the workplace [20]. Naturally, such approaches urge solution of problems related to the security of personal data of employees [7].

\section{Application of BD to Solve HRM Issues}

Opportunities provided by BV for HRM issues open up new prospects for companies to make wise decisions and forecast future situation. However, the realization of these opportunities requires the following problems to be solved [21, 22]:

$>$ HR problem - BD solely is insufficient for companies. They should have a group of leaders and personnel who are capable to, how, when, and where, use this data with better methods.

The staff must master various technical skills. Table 1 describes these skills [23, 24].

SAS reports that the number of BD workers averagely increased 10 times from 2008 to 2013. Moreover, they earn $£ 55,000$ per year, which is more than the salary of specialists in information technology by $2 \%$. SAS predicts that the demand for BD specialists will rise by $160 \%$ within the years 2013-2020, that is the number of jobs will reach 346000 [23, 24].

Table 1

Qualifications and skills of personnel required for BD

\begin{tabular}{|l|l|l|}
\hline & Qualifications & Required skills \\
\hline 1. & BD developer & NoSQL, Java, JavaScript, MySQL, Linux, CSS \\
\hline 2. & BD designers & $\begin{array}{l}\text { Oracle, Java, SQL, Hadoop, SQL } \\
\text { Server, data modeling, ETL, } \\
\text { enterprise architecture, analytics }\end{array}$ \\
\hline 3. & BD analysts & Oracle, SQL, Java, data modeling, ETL, analytics, data analysis \\
\hline 4. & BD administrator & Linux, MySQL, Puppet, Hadoop, Oracle, accident recovery \\
\hline 5. & BD project manager & $\begin{array}{l}\text { Oracle, Netezza, Business Objects, Hyperion, Agile Software } \\
\text { Development - PRINCE2 }\end{array}$ \\
\hline 6. & BD designer & $\begin{array}{l}\text { Oracle, SQL, Netezza, SQL Server, Informatics, MySQL, Unix } \\
\text { plus ETL, data modeling, analytics, CSS, } \\
\text { Unit Testing, Data Integration, Data Mining. }\end{array}$ \\
\hline 7. & Researcher on data & $\begin{array}{l}\text { Hadoop, Java, NoSQL, C++, artificial intelligent, Data Mining, } \\
\text { analytics }\end{array}$ \\
\hline
\end{tabular}


$>$ The scarcity in data science causes a number of restrictions in some sectors. BDA aims at creating conditions for individuals to make important decisions. It is carried out through involving data scientists capable to analyze large-scale data. This, in turn, leads to the formation of data science. Data science consists of numerous methods and theories related to mathematics, mathematical statistics, data engineering, recognition of images, advanced computing, visualization, uncertainty modeling, data warehouse, high performance computing [25]. The rise of digital sphere creates rich data sources and connection among them by structuring and analyzing the unstructured data. Data is constantly growing and the problems are changing in the competitive environment, where data allows the scientific decision-maker offering concrete solution without useless analysis.

$>$ Joint Use of BD with structured data. In fact, today BD is experiencing the joint use of related concepts and methods; however, these methods are still far from perfection [9]. Thus, the use of BD jointly with the traditionally structured data seems to be impossible. Because there is no the perfect method enabling such an opportunity, appropriate methods are still being developed.

$>$ Security of personal data of employees. In addition to the opportunities created by the development and application of BD, it is increasing the threats associated with the privacy and commercial secrets of people and businesses. IDC statistics shows that, in 2010, while only onethird of the data was protected, it will reach to two-fifth by 2020 [26, 27].

To appreciate the seriousness of the situation, the official website of the European Commission writes in the article "Protection of the employee's personal data": "[...] the places where the use of information technology to collect personal data in HRM need to strengthen and expand the organization of labor. Otherwise, there has been observed a deepening of the gap between workforce and personal life..." [28].

International experience shows that one of the main obstacles to the development of HRM systems is to ensure the confidentiality and security of personal data of the employees [28, 29]. Thus, any organization having access all data of its employees, must guarantee its safety and confidentiality. Any information about the employee should be confidential. irrespective of its carrier.

Security and protection of personal data of an employee is regulated by ISO 77799 standard adopted by the International Organization for Standardization in 2000 [30]. The standard bases on the BS 7799 standard on practices for Information Security Management adopted in 1995 in the UK. According to this standard, information security modes are provided by:

- the goal set by the organization and its security policy to achieve this goal - on organizational (administrative and procedural) level;

- information security guidelines for staff, as well as the development and implementation of physical protection measures - on procedural level;

- use of tested and certified solutions, the standard of the measures: keeping backups, antivirus and password protection, firewall, data encryption and etc. - on technical (hardware and software) level.

ISO 27002 standard was developed in 2013, based on ISO 77799 standard. The ISO 27002 standard includes "Guidelines for organizational information security standards and information security management practices including the selection, implementation and management of controls, taking into consideration the organization's information security risk environment". For the first time, this standard takes into account the features of security issues in specific areas (e.g., health care, manufacturing, etc.), the standard includes 14 control sections covering 114 elements [31].

\section{Conclusion}

Today, BDA is deemed more advanced and effective method of governance and predictability in decision-making. The joint use of BDA with data collected in HRM system provides more updates about the employees. Based on the obtained results, HRM specialists are 
able to feel transformations in this or any other business. This, in turn, will contribute to making proper decisions [32]. BDA allows HR managers to:

$>$ minimize financial costs and losses;

$>$ reduce the risk of new initiatives for personnel management and development;

implement better planning and prediction on organization's work to develop and support it on a single technology platform.

In this regard, successful relation of HRM with BD requires ensuring following stages:

$>$ scattered, sparse and inappropriate data should be avoided. The first step for this is the identification, that is, the data required to resolve specific HRM issue should be determined. HRM departments often store the data in different formats with traditional practices. BD identifies the data related to HRM from various information systems and defines the strategy for its integration;

$>$ use of a single interface. Successful strategy for BD processing bases on knowing how to collect the data within the organization. Automated collection and management of data by a single center must be provided;

starting from simple, i.e., once the type of data and the method of its collecting is identified, it is important to know which data should be analyzed. One should start from simple mutual relations to support effectiveness and simplicity, which helps to understand how to analyze BD and what results will be obtained. Only then, we can increase the complexity of the analysis, and deepen HRM forecasting and analytics.

Such an approach meets the objectives of company for realizing BD-based HRM-strategy.

\section{References}

1. Ingram Microdata center report on "4 Big Data Use Cases in the Manufacturing Industry", www.ingrammicroadvisor.com/big-data/4-big-data-use-cases-in-the-manufacturingindustry

2. www.cio.com/article/2386531/healthcare/healthcare-6-big-data-analytics-use-cases forhealthcare-it.html

3. Big Data in Human Resource Management - Developing Research Context, file://C:/Users/HP/Downloads/Big\%20Data\%20in\%20Human\%20Resource\%20Management $\% 20 . p d f$

4. Valle L.S., Lesser E., Shockley R., Hopkins M.S. and Kruschwitz N. Big Data, Analytics and the Path from Insights to Value // MIT Sloan Management Review, 2011, vol.52, no. 2, pp.74-82.

5. Scott C.W., Will T.A.H. Three Business and Societal Cases for Big Data: Which of the Three Is True? // IEEE Engineering Management Review, 2014, vol.42, no.3, pp.65-72.

6. Zang S., Ye M. Human Resource Management in the Era of Big Data // Journal of Human Resource and Sustainability Studies, 2015, no.3, pp.41-45.

file://C:/Users/HP/Downloads/JHRSS_2015031714271747\%20(1).pdf

7. Jabrayilova Z.G. Protection of personal data in human resource management systems // Information Society Problems, 2015, No 2, pp. 26-34.

8. Bellinger Gene, Durval Castro and Anthony Mills. "Data, information, knowledge, and wisdom." 1997/2004. http://courseweb.lis.illinois.edu

9. Big Data Big Data for HR. How to see the identity behind the figure? // Competence Journal.http://hr-media.ru/bolshie-dannye-bigdata-dlya-hr-kak-uvidet-lichnost-za-tsifroj/december-january 2015

10. "7 Reasons HR Technology Is So Hot Today" www.forbes.com/sites/joshbersin/2013/05/31/7-reasons-hr-technology-is-so-hot-today/

11. Huang S.L. and Xiang J. Big Data Light up "Wisdom" of Human Resources Management System // Science \& Technology for Chinese Mass Media, 2013, no.12, pp.76-78.

12. Dong X.H., Ying A., Guo J. G. Research on the Application of the Big Data Technology in the Network Recruitment // Human Resource Development of China, 2014, v.18, pp.37-41. 
13. www.equest.com/solutions/big-data-for-hr/

14. Tian H. The Concept, Thinking of Human Resources Management Based on the Era of Big Data // Human Resources, 2014, no.20, pp.162-163.

15. He Y. Management Innovation in "the Era of Big Data" // Human Resources, 2013, no.10, pp.62-63.

16. Zhou G.H. Thinking on Human Resources Management Based on the Value of Big Data // Science Mosaic, 2013, no.12, pp.104-107.

17. Wang D.H. Evidence-Based Human Resource Management in the Era of Big Data // Chinese and Foreign Entrepreneurs, 2013, no.8, pp.159-168.

18. Wu Z.Y. Research on Model of Human Resources Management System Based on Cloud Computing // China Computer \& Communication, 2012, no.8, pp.142-143.

19. Wei B. The Recruitment Management System Based on Cloud Computing Model // Science \& Technology Information, 2012, no.19, pp.108-109.

20. The Big Data Opportunity for HR and Finance. Harvard Business Review https://hbr.org/resources/pdfs/comm/workday/workday_report_oct.pdf

21. Capgemini Consulting: Big Data trends \& challenges www.consultancy.uk/news/1516/capgemini-consulting-big-data-trends-challenges

22. "BIG DATA: A Management Revolution" https://hbr.org/2012/10/big-datathe-management-revolution/ar

23. SAS report on "Big Data Analytics an assessment of demand for labor and skills, 2012-2017", 2013.

www.e-skills.com/Documents/Research/General/BigDataAnalytics_Report_Jan2013.pdf

24. SAS report on "Big Data Analytics assessment of demand for labour and skills, 2013-2020, 2014. www.e-skills.com/Documents/Research/General/BigData_report_Nov14.pdf

25. Liebowitz J. Business analytics: an introduction, 2013, 288 p.

26. Zhao J. How to Make the Enterprise Human Resources Management Adapt to Conditions during the Age of the Big Data // Human Resource Development of China, 2012, no.4, pp.13-16.

27. Meng X.F., Ci X. Big Data Management: Concepts, Techniques and Challenges // Journal of Computer Research and Development, 2013, no.50, pp.146-169.

28. http://ec.europa.eu/social/main.jsp?catId=708

29. Labour Code of the Russian Federation, www.consultant.ru/popular/tkrf/14_18.html\#p1884

30. www.praxiom.com/iso-17799-2000.htm

31. www.27000.org/iso-27002.htm

32. https://blogs.oracle.com/applications/entry/three_steps_to_get_big 